\title{
Methods of Clinical Assessment in Patients with Disorders of Consciousness, with an emphasis on Electrophysiological Evidence
}

\author{
Saied Sabaghypour* \\ Cognitive Neuroscience Laboratory, University of Tabriz, Iran
}

Submission: November 17,2017; Published: December 20, 2017

*Corresponding author: Saied Sabaghypour, PhD student in Cognitive Neuroscience, Cognitive Neuroscience Laboratory, University of Tabriz, Tabriz, Iran, Email: saied.sabaghy@gmail.com

\begin{abstract}
Consciousness still remains for some cognitive psychologists and neuroscientists a remote and unempirical problem, but computational methods and understanding neural correlates of consciousness has opened a new area of research with vast clinical applications. On one hand, with regard to brain imaging and stimulation techniques the problem of consciousness is more addressable than before, and on the other hand thanks to brain imaging tools, consciousness level assessment is made possible. The major issue in this new research area is that whether we can help clinical cases that are in altered states of consciousness and recover their normal life. In this review we will first introduce different kinds of consciousness disorders, i.e. coma, vegetative, locked-in syndrome and minimally conscious states. Then we will focus on the electrophysiological methods of clinical assessment in patients with disorders of consciousness
\end{abstract}

Keywords: Consciousness; Clinical assessment; Electrophysiology; Cognitive neuroscience

\section{Introduction}

The problem of consciousness raises many fundamental questions and these questions occupied the minds of many researchers for centuries. With the arrival of the nineteenth and twentieth centuries, due to the extreme behavioral approaches, the general belief was that the term "consciousness" does not have any studying value and is also a and severely ill-defined phenomenon. But the situation has changed since the late 80 's and consciousness became one of the main issues in psychology and cognitive neuroscience.

However, consciousness is still a non-empirical matter for some cognitive psychologists and neuroscientist, especially due to inconsistent definitions as well as less attention to developments in neurophysiology and brain imaging. Thus, the first step to bring the phenomenon of consciousness into the laboratory is to propose an operational definition and search for the related neural mechanisms of consciousness. The main principle for the scientific study of consciousness is to find the minimal differences between conscious and unconscious states using brain imaging techniques such as functional magnetic resonance imaging (fMRI) and electroencephalogram (EEG).
In the first part of this article we will review a variety of disorders of consciousness including coma, vegetative state, locking syndrome and minimally conscious state and in the second part we will focus on the main electrophysiological methods of clinical assessment in patients with disorders of consciousness.

\section{Disorders of Consciousness (DoC)}

Every year, thousands of patients go to coma for reasons such as traffic accidents, stroke, suicide attempt, carbon monoxide poisoning and drowning and some of them go to more severe states such as vegetative or locked-in syndrome. Typically after the traumatic brain injury (TBI), the patient may either go to coma or brain death state. In brain death, in accordance with "death diagnosis guideline 1981", the basic functions such as blood circulation, neuro endocrine systems and breathing are absent. If the patient survives from brain death, between two to four weeks he may go to the coma state [1]. After this period the patient may go to three different states: vegetative state, minimally conscious state or locked-in syndrome (Figure 1)[2]. 


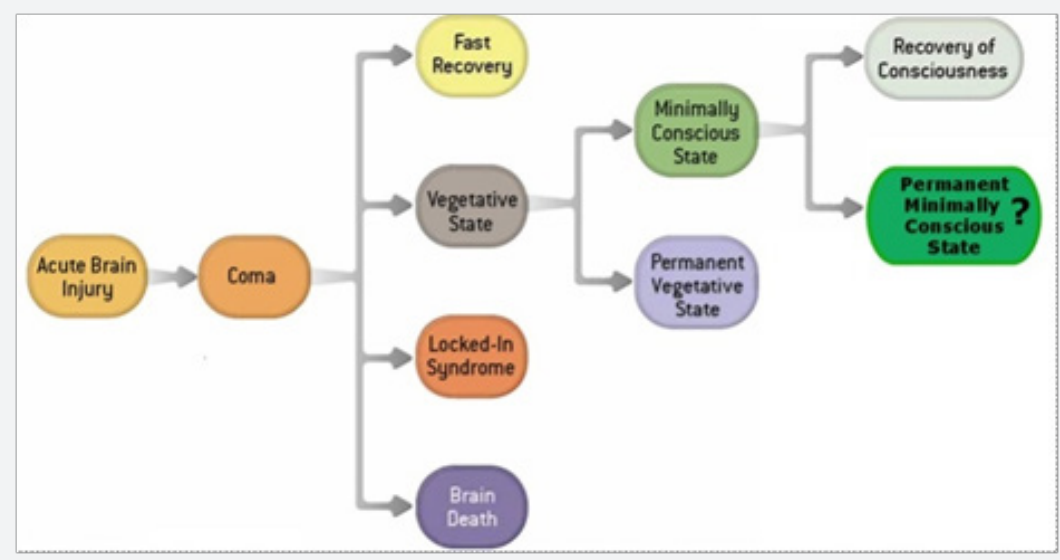

Figure 1: From coma to consciousness (adapted from Laureys $S$ et al. [2]).

\section{Vegetative state(VS)}

Vegetative state was first described by Jennet [3] as "an organic body capable of growth and development but devoid of sensation and thought". Autonomous activities including blood circulation, breathing and sleep-wake cycle are intact in this state, but the patient is not aware of the environment [2]. These patients may occasionally open their eyes, but these reactions are not related to external stimulus. If the patient remains in the vegetative state more than three to twelve months, the end-oflife decision has to be considered by the neurologists.

\section{Minimally conscious state (MCS)}

Arousal levels in minimally conscious state will remain intact and these patients sometimes show visible signs of consciousness [4] including emotional response to verbal stimuli, manipulation of objects and visual search. If any of these behaviors are seen in these patients, we can conclude that the transition from the vegetative state has taken place and they are in minimally conscious state.

\section{Locked-in syndrome (LIS)}

The locked-in syndrome is not considered as a disorder of consciousness, but because it is sometimes confused with the vegetative state is of utmost importance. Patients with locked-in syndrome are not able to move or speak, but can communicate with the outside world through blinking or vertical movements of the eyes [4].

\section{Electrophysiological Assessment of Disorders of Consciousness}

Brain imaging techniques have brought important advances in the study of consciousness. In fact, these techniques have shown us the minimal difference between conscious and unconscious states in normal subjects [5].

Functional magnetic resonance imaging (fMRI) have shown that in most cases when stimuli is presented less than 60 milliseconds to healthy subjects, they are not consciously perceived; while by increasing the presentation period, major changes in the cortical areas (especially parietal and prefrontal cortical areas) are observed [6].

Although functional magnetic resonance imaging is a useful tool to localize brain areas, it cannot tell us the exact timing of conscious processing [7]. In this case, brain imaging tools such as event-related potentials (ERP) and quantitative electroencephalogram ( $\mathrm{qEEG}$ ) are used to extract related components of sensory and cognitive functions.

\section{Evoked and event-related potentials}

Electrophysiological assessment of disorders of consciousness with regard to evoked potentials can be divided into two categories: short latency evoked responses and long latency event related potentials (ERPs). The first one is related to the physical properties of stimuli and its conduction in the nervous system and the second one is related to its psychological properties.

Somatosensory evoked potential (SSEP) which is elicited by stimulation of the median nerve is one of the short latency evoked potentials, and leads to the N20 component. A number of studies [8-10] show that bilateral absence of the N20 component is a good indicator of poor outcome in patients with disorder of consciousness (with 99 to 100 percent accuracy). Brainstem auditory evoked potential (BAEP) is another short latency evoked potential which is elicited $10 \mathrm{~ms}$ after stimulation and shows the functional working of the auditory nerve. The absence of this potential also is significantly related to poor outcome, but it has a lower predictive value than the N20 component [11]. Examination of these early components is a good indication of poor outcome for the patients, but their presence will not guarantee the return of consciousness.

Event-related potentials (ERPs) on the other hand are predictors of awakening. These components show advanced cerebral processes and may indicate the presence of consciousness. The mismatch negativity (MMN) and P300 are two examples of these late potentials. 
MMN is a negative component which is elicited between 100 and $200 \mathrm{~ms}$ after a change or odd sound in a serious of repeated similar sounds. It is an automatic response and does not need the subject's attention. Studies have shown [12] that MMN beholds important predictive value. In fact, the absence of MMN is highly associated with an absence of recovery in 91 to 93 percent of cases.

The P300 is another ERP component which is elicited 300 $\mathrm{ms}$ after the presentation of the stimulus and is modulated by attention of the subject. The presence of P300 component is another predicator of recovery of consciousness but it can also be used as a tool for differential diagnosis of MCS and VS patients (Figure 2) [13].

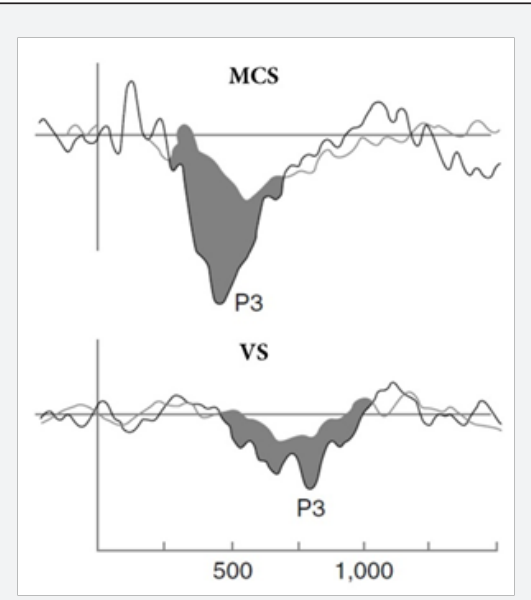

Figure 2: Differential diagnosis value of $\mathrm{P} 300$ component in response to the own name (adapted from Perrin F et al. [13]).

\section{qEEG methods for differential diagnosis of disorders of consciousness}

Quantitative electroencephalography (qEEG) uses mathematical algorithms and extracts measures from raw EEGs. The power spectral density and the bispectral index (BIS) are two methods which can be used for differential diagnosis of MCS and VS patients. The power spectral density, which is obtained with FFT algorithm, is higher in lower frequencies in VS patients and is lower in higher frequencies in MCS patients (Figure 3) [14].

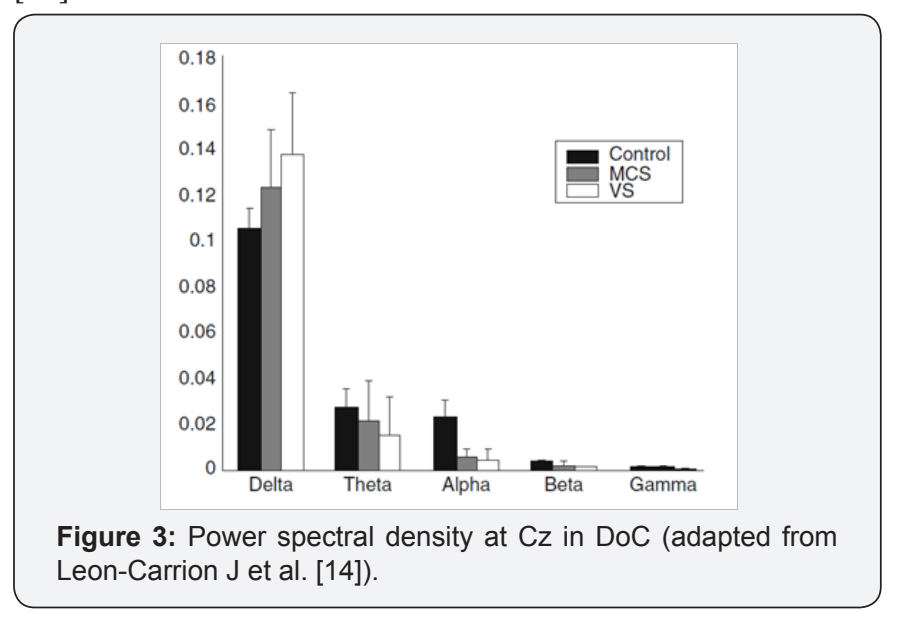

The BIS is a measure with one digit from 0 (inactive EEG) to 100 (normal EEG) which is obtained from temporal and frequency parameters. Studies have shown that VS patients have a lower BIS value than MCS patients and therefore the value of BIS can be also used as a tool for differential diagnosis (Figure 4) [15].

\section{Conclusion}

In conclusion the scientific study of consciousness shows that there is evidence that evoked and event-related potentials could help refine clinical predictions of outcome from coma. Evoked potentials are reliable predicators of poor outcome and event-related potentials on the other hand can be used to predict good outcome. Quantitative EEG allows various objective measurements of the cerebral activity providing information on the patient's consciousness level. Encouraging results have shown differences between groups of patients according to the diagnosis.

The methods discussed in this article are inexpensive and non-invasive tests that can be safely recorded at the patient's bedside. Thus, the neurologists need experience to be aware of these new tools and their utmost important clinical values.

\section{References}

1. (1981) Guidelines for the determination of death. Report of the medical consultants on the diagnosis of death to the President's commission for the study of ethical problems in medicine and biomedical and behavioral research. JAMA 246(19): 2184-2186.

2. Laureys S, Perrin F, Schnakers C, Boly M, Majerus S (2005) Residual cognitive function in comatose, vegetative and minimally conscious states. Current Opinion in Neurology 18(6): 726-733.

3. Jennett B (1975) 30 years of the vegetative state: clinical, ethical and legal problems.

4. Joseph TG, Ashwal S, Childs N, Cranford R, Jennett B, et al. (2002) The minimally conscious state: definition and diagnostic criteria. Neurology 58(3): 349-353.

5. Dehaene S (2014) Consciousness and the brain: Deciphering how the brain codes our thoughts. Viking Penguin.

6. Dehaene S, Naccache L (2001) Towards a cognitive neuroscience of consciousness: basic evidence and a workspace framework. Cognition 79(1-2): 1-37.

7. Sergent C, Baillet S, Dehaene S (2005) Timing of the brain events underlying access to consciousness during the attentional blink. Nature neuroscience 8: 1391-1400.

8. Pfeiffer G, Pfeifer R, Isenmann S (2014) Cerebral hypoxia, missing cortical somatosensory evoked potentials and recovery of consciousness. BMC Neurology 14: 82.

9. Stanziano M, Foglia C, Soddu A, Gargano F, Papa M (2011) Post-anoxic vegetative state: imaging and prognostic perspectives. Funct Neurol 26(1): 45-50.

10. Deng R, Xiong W, Jia X (2015) Electrophysiological monitoring of brain injury and recovery after cardiac arrest. International Journal of Molecular Sciences 16(11): 25999-26018.

11. Robinson LR, Micklesen PJ, Tirschwell, DL, Lew HL (2003) Predictive value of somatosensory evoked potentials for awakening from coma. Critical care medicine (31): 960-967. 


\section{Open Access Journal of Neurology \& Neurosurgery}

12. Fischer C, Luaute J, Morlet D (2010) Event-related potentials (MMN and novelty P3) in permanent vegetative or minimally conscious states. Clin Neurophysiol 121(7): 1032-1042.

13. Perrin F, Schnakers C, Schabus M, Degueldre C, Goldman S, et al. (2006) Brain response to one's own name in vegetative state, minimally conscious state, and locked-in syndrome. Arch Neurol 63(4): 562-569.
14. Leon CJ, Martin RJF, Damas LJ, Barroso YMJM, Dominguez MMR (2008) Brain function in the minimally conscious state: a quantitative neurophysiological study. Clin Neurophysiol 119: 1506-1514.

15. Schnakers C, Ledoux D, Majerus S, Damas F, Lambermont B, et al (2008) Diagnostic and prognostic use of bispectral index in coma, vegetative state and related disorders. Brain Inj 22: 926-931.
Your next submission with Juniper Publishers will reach you the below assets

- Quality Editorial service

- Swift Peer Review

- Reprints availability

- E-prints Service

- Manuscript Podcast for convenient understanding

- Global attainment for your research

- Manuscript accessibility in different formats

( Pdf, E-pub, Full Text, Audio)

- Unceasing customer service

Track the below URL for one-step submission https://juniperpublishers.com/online-submission.php 